\title{
A materialidade de uma cultura imaterial: aspectos da cultura material da Capoeira no Rio de Janeiro no século XIX
}

\author{
Ricardo Martins Porto Lussac*
}

\begin{abstract}
Resumo
A História da Educação cada vez mais debruça seu olhar sobre práticas não escolares da educação, entendendo que esta é realizada dentro de um mosaico de interações sociais. Compreender as utilidades e os significados dos aspectos materiais envolvidos na transmissão de práticas culturais é um fator fundamental e determinante para se conhecer os processos educativos envolvidos em qualquer fenômeno sociocultural em que habite uma relação de ensino-aprendizagem. Este artigo objetivou investigar a cultura material do patrimônio cultural imaterial que é a Capoeira, e seus processos pedagógicos no Rio de Janeiro no século XIX. Este estudo ilumina parcialmente a complexa relação dos sujeitos que desenvolveram o modo de fazer a Capoeira - cultura imaterial - com os objetos, materiais e ambientes que compuseram a cultura material do jogo-luta, e suas respectivas simbologias, bem como o seu modo de transmissão e aprendizagem no período estudado.
\end{abstract}

Palavras-chave: Capoeira; Cultura Material; História.

\section{The materiality of an immaterial culture: aspects of material culture of Capoeira in Rio de Janeiro in the} nineteenth century

\begin{abstract}
The history of education increasingly focuses on non-school education practices, understanding that this is done within a mosaic of social interactions. Understanding the uses and meanings of the material aspects involved in the transmission of cultural practices is an essential and determining factor to know the educational processes involved in any sociocultural phenomenon that inhabits a relationship of teaching and learning. This article aimed to investigate the material culture of the intangible cultural heritage that is Capoeira, and its pedagogical processes in Rio de Janeiro in the nineteenth century. This study partially illuminates the complex relationship of individuals who developed the way of doing Capoeira - immaterial culture - with objects, materials and environments that formed the material culture of the play-fighting, its symbols, and its mode of transmission and learning during the studied time.

Keywords: Capoeira; Material Culture; History.
\end{abstract}

\section{Introdução e Problemática}

Na última década no Brasil o Ministério da Cultura - MinC - dispensou atenção especial à área da cultura imaterial do país, desenvolvendo, neste sentido, políticas públicas e o respectivo registro e salvaguarda de determinadas práticas culturais.

Em 2008, a Capoeira, prática corporal de jogo-luta de origem brasileira, foi registrada pelo Instituto do Patrimônio Histórico e Artístico Nacional - IPHAN -, órgão subordinado ao MinC, como Patrimônio Cultural Imaterial do Brasil, por meio do registro das Rodas de Capoeira no Livro das Formas de Expressão e do Ofício dos Mestres de Capoeira no Livro dos Saberes.

Este fato fez com que antigas e novas discussões no campo do jogo-luta emergissem sob um novo contexto. Ao mesmo tempo, o recente campo de pesquisa sobre a Capoeira como patrimônio e como cultura imaterial começa a galgar suas primeiras abordagens e pesquisas, como por exemplo, os apontamentos de Vassalo (2008). Neste cenário, consequentemente, um dos fatores que veio a baila foi a busca pela melhor compreensão sobre a transmissão e respectivos processos educativos destas práticas, proporcionando um vasto campo de atuação para os pesquisadores de diferentes áreas, dentre elas, a Educação.

Por outro lado, o campo da História da Educação tem cada vez mais debruçado seu olhar em práticas não escolares da educação, na transmissão de conhecimentos e cultura nos mais diversificados grupos sociais. Isto ganha significância na medida em que se compreende que a educação é realizada dentro de um mosaico de atividades e interações sociais.

Neste sentido, por ser campo do conhecimento que ainda necessita de maiores investigações, não é de se estranhar que a literatura existente nesta área seja insuficiente para se compreender tais fenômenos. Compreender as

\footnotetext{
* Endereço eletrônico: ricardolussac@yahoo.com.br
} 
utilidades, os significados e as influências dos aspectos materiais envolvidos na transmissão de uma prática cultural é um fator fundamental e determinante para se conhecer os processos educativos envolvidos em qualquer fenômeno sociocultural em que habite uma relação de ensinoaprendizagem.

Sob esta perspectiva, torna-se imperativo aprofundar as pesquisas que contemplam os processos pedagógicos envolvidos na transmissão de práticas culturais como a da Capoeira. No caso desta, por ser um patrimônio brasileiro, ainda se faz necessário compreender melhor como este saber foi transmitido ao longo da história, para que, deste modo, se possa desenvolver um plano de preservação eficaz, visto que, um dos aspectos essenciais em planos de salvaguarda de patrimônios culturais imateriais é a transmissão (UNESCO, 2003).

\section{Objetivos e Metodologia}

Por tais motivos, este artigo teve como objetivo investigar a cultura material da Capoeira, a fim de conhecer os aspectos da materialidade envolvidos nos processos de ensino-aprendizagem do jogo-luta no Rio de Janeiro no século XIX, e compreender, a reboque o desenvolvimento de seus respectivos processos pedagógicos no decorrer da história.

O pouco que se pesquisou, mesmo que de forma não específica, sobre os aspectos materiais presentes na transmissão da Capoeira no século XIX no Rio de Janeiro pode ser verificado nos estudos de Soares (2002), autor que, em razão de contribuições relevantes para a historiografia, serviu como base na investigação deste artigo. Deste modo, a fim de oferecer maior embasamento à construção teórica do estudo, este também se valeu de fontes primárias do período estudado, como ofícios do Arquivo da Marinha, do Acervo Geral da Cidade do Rio de Janeiro, e registros policiais e processos judiciais encontrados no Arquivo Nacional, no Rio de Janeiro.

Apesar de não abordar a Capoeira como patrimônio, este artigo utilizou Vassalo (2008) que aborda esta temática na medida em que esta se refere às relações de transmissão e simbologias de culturas imateriais. Do mesmo modo, por ser a Capoeira entendida como uma cultura imaterial, o estudo não se deteve nesta perspectiva, e sim, teceu as relações da cultura imaterial e material da Capoeira. Para isso, além da autora citada acima, foram investigados textos do IPHAN (2011) e da UNESCO (2003), por serem organizações responsáveis por políticas públicas e pesquisas nesta área, os quais fundamentaram princípios essenciais utilizados para delimitar conceitualmente a cultura material, como já visto.

Os referenciais teóricos foram analisados por meio de interpretações de suas diferentes abordagens e enfoques, buscando as contribuições científicas que estes puderam somar. As fontes tiveram um tratamento qualitativo e interpretativo, e o cuidado de uma crítica interna referente ao conteúdo e significado da fonte ou documento, com o objetivo de verificar até que ponto apresentam coerência com as informações sobre o mesmo fato ou fenômeno colhidos em outras fontes, ao mesmo tempo em que se buscou entender o diálogo construído entre as fontes secundárias e primárias. A construção e a exposição dos argumentos foram desenvolvidas e apresentadas de forma cronológica e progressiva, relacionando os diferentes elementos e acontecimentos, obedecendo a uma sequência temporal e um encadeamento lógico.

Este artigo teve o recorte temporal definido ao século XIX. No início deste período constata-se o início da ocorrência da Capoeira no Rio de Janeiro e no Brasil e, ao final do mesmo, a prática da capoeira já era considerada crime, sendo fortemente reprimida. Já a definição da cidade do Rio de Janeiro como delimitação geo-social para a pesquisa se deu em razão da quantidade e qualidade das fontes, e por ser o local onde ocorreram os primeiros fatos e a maior ocorrência na história do jogo-luta da Capoeira no período proposto para a pesquisa.

Justifica-se, portanto, a busca pelo entendimento de como e o quê desta cultura é e foi transmitida no decorrer da história, pois de acordo com Simone Pondé Vassalo (2008, p. 1): “... a noção de patrimônio parece estar intimamente relacionada à de propriedade, seja ela de um indivíduo ou grupo social, e também à de herança, o que implica na sua transmissão e continuidade ao longo do tempo ...". Deste modo, torna-se interessante investigar a relação das culturas material e imaterial da Capoeira a fim de compreender o ensino-aprendizagem do jogo-luta ao longo da história.

Destarte, ao adentrar neste campo foi necessária uma delimitação conceitual sobre cultura material: no estudo não se abordou esta sob a perspectiva de um patrimônio material igualmente como define a UNESCO, concepção também 
compartilhada pelo IPHAN, e sim sob o conjunto de instrumentos, objetos, artefatos e lugares culturais que são associados às práticas, representações, expressões, conhecimentos e técnicas pertencentes a um determinado grupo que possui um saber específico de um modo de fazer e de uma forma de expressar uma cultura imaterial, que é transmitida aos seus pares por uma pedagogia própria.

O corpo deste artigo seguiu uma estratégia de abordagem pelas diferenças das nuances da cultura material da Capoeira. Após uma interpretação preliminar, optou-se por enquadrá-la em quatro aspectos: lugares, indumentárias, música e armas e objetos. Sob este entendimento, por mais investigada e analisada de modo separado a cultura material da Capoeira, estas análises não foram estanques, e sim enredadas para uma maior compreensão do fenômeno, pois tais partes compõem todo um arcabouço com o qual se pôde começar a interpretar e entender o mosaico da dinâmica dos processos pedagógicos presentes na Capoeira.

\section{Lugares}

A Capoeira proliferou-se endemicamente nos portos como no Rio, Bahia e Recife, sendo os portos durante todo o período Colonial e Imperial brasileiro, o canal de saída e entrada de tudo o que vinha de além-mar e, justamente, onde a capoeiragem mais se desenvolveu e disseminou. Os portos sempre foram locais onde se pode verificar práticas de lutas de acordo com as especificidades culturais.

É sabido que, no Brasil, os marinheiros de diversas nacionalidades eram considerados um tipo turbulento e perturbador da ordem nas ruas, embriagando-se facilmente. No início do século XIX, no Rio de Janeiro, frequentemente se socializavam aos negros e escravos, propiciando outros tipos de relações e trocas culturais e de informações (SOARES, 2002, p. 85, 86, 268 e 269).

Pode-se afirmar que o local onde houve contato certo e diversificado entre homens do mar e capoeiras foi o Arsenal da Marinha (ibidem, 2002, p. 302 e 303). O Arsenal da Marinha foi um dos principais locais de aglutinação de presos por capoeira na primeira metade do século XIX - como Soares (2002) demonstrou em seu trabalho - que também deixou de ser apenas um local de punição e passou a ter "um papel central na socialização escrava e nas trocas entre escravos e homens do mar" (SOARES, 2002, p. 275), como é possível constatar: "Sem o menor aviso, o soldado deu uma cabeçada no tal Joaquim". . O soldado em questão era um dos que guardavam os sentenciados do vasto complexo prisional que era o Arsenal de Marinha, local para onde eram remetidos a maior parte dos presos por capoeira no segundo quartel do século XIX. A esse respeito Soares afirma que a cabeçada, golpe típico da capoeiragem escrava da primeira metade do século XIX, presente entre os soldados no meio militar, é reflexo da longa presença dos capoeiras no presídio do Arsenal de Marinha da corte no Rio de Janeiro (ibidem, 2002, p. 248).

A presença de marinheiros em terra após o escurecer chegou a ser proibida em 1831, apesar de não surtir efeito. A noite era o horário preferido tanto para marujos como para os capoeiras se reunirem e perpetrarem outras atividades. O ambiente noturno, portanto, pode ser identificado como um dos aspectos importantes da cultura material da Capoeira, se diferenciando do diurno pelas condutas e comportamentos dos capoeiras. Vários fatores, como o recrutamento, aproximavam capoeiras e marinheiros (ibidem, 2002, p. 290). Como afirma Soares, "Muitas vezes, o capoeira e o marujo habitavam o mesmo indivíduo" (2002, p. 290): “[...] foi preso no meu distrito o preto Firmino, que diz ser forro e praça de marinheiro a bordo da Escuna de Guerra Itaparica por estar com outros pretos em capoeiragem [...]".

É possível que este ferimento na cabeça seja derivado do recebimento ou da aplicação de uma cabeçada, golpe clássico da capoeira neste período, indicando a prática do jogo-luta.

Soares (2002) desenvolveu a teoria de que a divisão entre as maltas de capoeira, com seus respectivos territórios, em Nagôs e Guaiamuns era ligada à divisão entre escravos - africanos - e livres ou libertos - crioulos. A área de Santa Rita e Candelária seria o ponto central para os crioulos ou livres. Este autor afirma que é possível que a presença de marinheiros, de várias nacionalidades, esteja relacionada a isso (ibidem, 2002, p. 320). Deste modo, é possível considerar a grande influência da marinhagem no desenvolvimento da Capoeira.

D. João VI foi quem abriu os portos brasileiros ao comércio estrangeiro, propiciando uma grande troca de informações com outras culturas de diferentes nações. Antes disto, estrangeiros nem sempre eram bem-vindos, sendo que muitas tripulações não podiam sequer desembarcar. Soma-se a este fato a política do governo português de isolamento do interior das 
capitanias, resultando em ignorância e falta ou atraso de comunicação com o restante do mundo e seus respectivos acontecimentos. Desde a terceira década do século XVIII abrir estradas era proibido por lei, impedindo a comunicação entre as capitanias pelo sertão, no intuito de dificultar o contrabando de ouro e pedras preciosas e ainda facilitar a fiscalização. Neste sentido, é compreensível verificar o transporte por poucas estradas e principalmente pelos portos, mais fáceis de fiscalizar (GOMES; NOGUEIRA, 2008). Eram nos portos onde se encontrava informação e a possibilidade de comunicação com o mundo e encontro de pessoas, práticas e culturas.

É importante considerar ainda que no início da colonização do Brasil os portos mais importantes, além de o do Rio de Janeiro, eram o de Recife - em Pernambuco, o de Salvador - na Bahia e, no início da colonização, o de São Vicente em São Paulo. Mas foi somente no início do século XIX no Rio de Janeiro que a Capoeira se manifestou inicialmente e de forma mais intensa. A cidade do Rio de Janeiro era um dos portos mais bem localizados no mundo, pois propiciava a ligação e o comércio com diferentes partes da América, a Europa, a África, Índias Orientais e as ilhas dos mares do sul (MARY DEL PRIORE In: GOMES; NOGUEIRA, 2008).

Os navegadores, além de ligar diferentes partes do Brasil, poderiam ter trazido desde técnicas de lutas europeias às africanas, e também do oriente, considerando que a Índia, junto com a China, além de ser vista como uma das regiões cujas artes marciais tiveram origem, era rota e caminho para estes navegantes. A rota de navegação para a Índia passava por boa parte do litoral da África, continente o qual deve-se levar em conta, que também pode ser considerado como o berço das práticas de combate corporal nos primórdios da civilização. Quanto a uma influência chinesa, é oportuno lembrar que chineses estiveram no Brasil para o plantio de chá no Jardim Botânico na época de D. João VI. Os portugueses com suas viagens às Índias também já acrescentavam alguns traços orientais na cultura brasileira.

Como a cidade do Rio de Janeiro era um centro cosmopolita, do qual sua cultura irradiava para o restante do país, é possível pensar que a Capoeira do Rio de Janeiro, além de ter sido exportada por meio do mar carioca para outros lugares do Brasil, pode ter também catalizado um processo comum de consolidação da Capoeira como expressão e manifestação de luta em outras capitais e cidades do Brasil ao longo do século XIX. Outro ponto que deve ser aprofundado em futuras pesquisas é a possibilidade de presos na capital do Império advindos de outras regiões do Brasil, principalmente após as revoltas ou levantes, terem levado o conhecimento do jogo-luta da Capoeira do Rio de Janeiro para outras províncias brasileiras, ao retornarem para suas terras após a libertação ou fuga.

De acordo com Gil Cavalcanti (2008), também conhecido como Mestre Gil Velho, no século XIX, "diversos movimentos ligados ao universo portuário apresentaram formas de organização identitária e territorial semelhantes. Eram as gangues de rua, movimentos sociais anárquicos que tinham como ponto de conexão o porto".

A capoeira do século XIX, no Rio, com as maltas de capoeira, e em Recife, com as gangues de rua dos Brabos e Valentões, foram movimentos muito semelhantes aos das gangues de savate (boxe francês) em Paris e das maltas de fadistas de Lisboa do século XIX (CAVALCANTI, 2008).

O autor comenta que, além de serem cidades metropolitanas portuárias, proporcionando a troca de ideias e influências entre nichos socioculturais parecidos, há várias semelhanças entre a Capoeira do Rio de Janeiro e de Recife, desde a indumentária, aos gestos e golpes típicos da capoeiragem, e inclusive no modo de organização identitária e territorial semelhantes - em maltas, como eram denominadas as gangues - por estarem inseridos em contextos e realidades similares (ibidem, 2008). Cavalcanti (2008) entende que os estudos sobre o desenvolvimento da Capoeira devem abarcar as realidades contextual e histórica dos sujeitos, criadas sob a perspectiva identitária e territorial.

Outro ponto interessante quando se fala na relação Capoeira e portos é o termo ginga, que significa balanço e provém da marinhagem. Inclusive, é sabido o uso comum de facas e outras ferramentas e utensílios similares por marinheiros, o que poderia sugerir a fácil absorção das armas brancas curtas de corte por parte dos praticantes da Capoeira, principalmente no Rio de Janeiro do Século XIX. Outra explicação para a preferência por armas brancas curtas de corte era o seu fácil e rápido manejo, por sua periculosidade e a possibilidade de ocultação ou dispersão da mesma. 
Todos estes fatores contribuem para a construção de um cenário contextual onde a cultura material do lugar está intimamente ligada aos artefatos e fazeres próprios do local e dos respectivos sujeitos.

Os portos e seus arredores seriam, portanto, segundo a maioria das evidências, os berços originários da Capoeira, de sua eclosão, e até os seus centros de irradiação. Poderia a Capoeira ser praticada durante algum momento de folga dos trabalhadores do porto, da estiva, como jogo, simulação de luta e ainda com imbricações sociais mais específicas, como a delimitação de espaços geográficos, físicos, temporais, de trabalho, no amor, nos grupos, nas hierarquias, entre outros. No início do século XIX, o Cais do Valongo no Rio de Janeiro, era o local onde desembarcavam os escravos - "africanos novos" - recém chegados da África por meio dos navios negreiros, e também onde estes ficavam de quarentena até poderem ser vendidos na Cidade Velha. O Cais do Valongo estava localizado nas proximidades da Freguesia do Sacramento - área de grande concentração de comércio e da população escrava do Rio e "centro nervoso" de atuação das maltas de capoeira (SOARES, 2002, p. 177):

As regiões circunvizinhas ao cais, como o morro do Livramento e as ruas próximas, mantinham forte população africana negra, liberta ou livre, razão por que seriam conhecidas futuramente como "pequena África" do Rio de Janeiro. Esta ausência indica que a capoeira não fosse, talvez, um espaço aberto para o boçal ou o africano novo, mas um patamar que só podia ser alcançado pelo ladino, ou crioulo já familiarizado com a sociedade escravista colonial (ibidem, 2002, p. 177 e 178).

Deste modo, Soares ratifica a Capoeira do início do século XIX no Rio de Janeiro, com o seu conjunto de fazeres e saberes de sua época, como um tipo de prática social, impregnada por elementos de identidade cultural, fatores agregatórios e de pertencimento social, aos quais conduzem ao raciocínio de ser a Capoeira realmente uma prática cultural eminentemente brasileira, visto os próprios africanos recém chegados serem obrigados a alcançar um 'patamar' para fazerem parte do círculo sociocultural da capoeiragem.

A Capoeira era a maior expressão do inconformismo escravo no Rio de Janeiro durante todo o século XIX, principalmente na primeira metade deste período. Este inconformismo era encontrado em outros locais da cidade além da zona portuária e tinha características próprias que a prática do jogo-luta da Capoeira envolvia:

A capoeira escrava tinha várias faces. Ela era também o lúdico, a brincadeira, o jogo, embora a natureza da documentação produzida sobre o fenômeno pouco revele a respeito deste ângulo. Por outro lado, ela era também um jogo de posições estabelecido no interior da comunidade negra-escrava da cidade, expresso no controle dos chafarizes - ponto de encontro inevitável dos cativos da cidade - e, depois, das praças públicas. Um jogo mortal, que, nas décadas de 1830 e 1840, era decidido principalmente à noite, quando grande parte dos habitantes e senhores da cidade estavam em suas casas e apenas as patrulhas policiais interferiam no silêncio noturno, de quando em vez interrompido pelo dobre dos sinos do "Aragão" (SOARES, 2002, p. 575 e 576).

Assim como a zona portuária, as ruas e praças públicas, os chafarizes eram pontos importantes de encontro. Disputados pela classe escrava e por capoeiras, era comum a instalação de postos de guarda próximo aos chafarizes, dentre outras medidas tomadas pela ordem e segurança pública - como é possível encontrar em ofício de 25 de fevereiro de 1836: “[...] necessidade que há de uma guarda por pequena que seja no chafariz denominado Lagarto justamente no $2^{\circ}$ quarteirão, onde os negros capoeiras continuadamente ali vão fazer desordens". 3

Um outro costume dos capoeiras do Rio de Janeiro da primeira metade do século XIX é a escalada das torres das igrejas para badalar os sinos, em um gesto e demonstração de habilidade, coragem e masculinidade, não raros sendo os acidentes fatais. Mas de acordo com Soares, as informações sobre este "dispositivo típico da capoeira escrava" desaparecem completamente na segunda metade do século XIX (2002, p. 240).

Ao analisar este comportamento, além de ser uma ação que envolvia alto grau de perigo, denotando coragem e ousadia, a qual poderia ser um rito de passagem ou uma simples prova de masculinidade, esta ação também significava o desafio à ordem e a dominação de um símbolo de poder: o alto da torre de um prédio da Igreja 
Católica, onde, geralmente, ficava seu maior símbolo - a cruz - e também, o sino - que controlava as horas e momentos dos dias e, inclusive, os anúncios festivos, os toques de recolher, entre outros avisos e comunicados.

Já no início da segunda década do século XIX, a Capoeira podia ser encontrada até em regiões periféricas da cidade do Rio de Janeiro, longe do centro urbano, evidenciando sua grande zona de ocorrência, mesmo que de forma mais esporádica: "João e Manuel, aparentemente crioulos, foram presos jogando capoeira em frente à fábrica de pólvora, na Alagoa. Cada um recebeu cem açoites" . Para se ter uma ideia da distância do centro da cidade, a fábrica de pólvora em questão funcionava em um prédio que pode ser encontrado atualmente dentro do Jardim Botânico.

Ao longo do século XIX a Capoeira gradualmente ocupou os espaços da cidade do Rio de Janeiro. Desde os mais afastados aos mais movimentados e desejados pela escravaria urbana. Presente nas relações de poder entre grupos, os lugares aos quais habitava forneceram as condições para forjar sua cultura e identidade.

Os portos, canais de entrada e saída para o mundo, propiciavam uma grande troca de informações - em geral, em 'primeira mão', de culturas e de toda a sorte de mercadorias e materiais. O porto é o lugar onde tudo chegava primeiro, influenciando sobremaneira o comportamento daqueles que por ali transitavam, entre eles, os capoeiras.

Deste modo, os lugares podem ser entendidos como ativos e importantes fatores da cultura material no desenvolvimento da prática cultural da Capoeira. O cotidiano nos portos, nos chafarizes - ponto de encontro das freguesias e, respectivamente, das maltas que dominavam estes espaços -, nas praças públicas e ruas nas quais a prática da capoeiragem foi proibida pelo Código Penal de 1890, forjaram a cultura urbana da Capoeira e, consequentemente, os modos de fazer e os saberes envolvidos nas práticas destes sujeitos.

\section{Indumentárias}

Os capoeiristas dos dias de hoje sempre se reportam ao passado da Capoeira no intuito de fundamentar suas ações, seu modo de ser e, inclusive, quanto ao uso de determinados materiais. Não é por acaso que o lenço de seda, utilizado pelos capoeiras do Rio Antigo para proteção do pescoço contra o corte das navalhas ou a corda que amarrava as calças dos escravos, hoje sejam usados como símbolo em ritual de passagem de hierarquia por alguns grupos de Capoeira. Os exemplos de utilização neste sentido são muitos.

Como já colocado, novamente aqui cabe a afirmativa de Simone Pondé Vassalo, pois a “... noção de patrimônio parece estar intimamente relacionada à de propriedade, seja ela de um indivíduo ou grupo social, e também à de herança, o que implica na sua transmissão e continuidade ao longo do tempo ..." (2008, p. 1). Deste modo, justifica-se a busca pelo entendimento de como e o quê desta herança, material ou imaterial, é e foi transmitida ao longo do tempo.

No Rio de Janeiro do século XIX a indumentária da escravaria urbana detinha certos detalhes que podiam ser percebidos como comuns aos capoeiras. Eram fitas, barretes e penas coloridas, chapéus, entre outros que podem ser percebidos nas fontes primárias em que aparece a prática do jogoluta da Capoeira: "Manoel Angola foi preso com um barrete e fitas vermelhas, jogando capoeira." ; "Manuel Angola de Custódio de tal, por ser encontrado com um barrete e fitas encarnada jogando capoeira [...]"6; "José Calabar foi preso jogando capoeira com uma pena branca na cabeça"7 "Antonio Cassange desafiou para cabeçadas o paisano Antônio Moreiro portando uma fita de cor na mão"8.

A utilização destes elementos em seu vestuário poderia ocorrer por inúmeros motivos os quais se poderia especular, como a ausência ou carência de peças na indumentária, o desejo de se parecer ou de se igualar aos seus pares mais bem sucedidos ou mesmo à classe escravocrata, entre outros. Mas os aspectos simbólicos e representativos envolvidos nestes aspectos materiais poderiam também portar significados mais profundos. Soares cita Thompson \& Cornet, os quais afirmam: "Cristóvão Cassange foi preso por estar jogando capoeira e trazer dois chapéus cravados de alfinetes com as pontas para fora. Eles se assemelham aos minkise, figuras sagradas da arte congo, que afastam maus espritos" (THOMPSON \& CORNET apud SOARES, 2002, p. 148). Isto sugere que os escravos reconfiguravam seus aspectos de representação simbólico-material africanos com os artefatos os quais tinham acesso.

Jogar Capoeira portando fitas poderia ser algum tipo de identificação ou código para se praticar algo reprimido, ou mesmo, para a identificação de seus pares entre grupos sociais.

Os chapéus até os dias atuais são 
importantes elementos na indumentária de alguns capoeiristas, e sempre estiveram presentes na composição da vestimenta dos capoeiras. Na Corte tinha um aspecto de identidade, pertencimento e status na escravaria urbana. Eram itens desejados: "João Benguela deu uma cabeçada em um livre para furtar-lhe um chapéu" ". Soares afirma que no final de 1819 aumenta o número destes crimes (2002, p. 150). Os chapéus eram inclusive utilizados também pelas mãos como escudo de defesa contra armas brancas e também para ludibriar o olhar dos adversários quando em uma peleja, assim como se faz hoje em dia na Capoeira.

As indumentárias descreviam o status social, a função, entre outras características do povo. Mas só após a metade do século XIX, podem ser percebidas as diferenças entre as indumentárias dos Capoeiras, quando estes as assumem em suas roupas, cintos, calçados e chapéus. Estas diferenças são características de identidade de grupo que dialogam também com a prática do jogo-luta, como é o caso das cores que identificam as maltas e o corte das calças que facilitam os movimentos dos golpes e a ocultação de objetos e armas brancas.

Mas na litografia Jogar Capoëra de Rugendas (1998), onde a Capoeira é representada, as indumentárias dos sujeitos representados não apresentam elementos tão distintivos, os quais se poderiam identificar grupos definidos ou mesmo maltas, conforme se pode constatar nas décadas finais do século XIX no Rio de Janeiro, quando as cores encarnada e branca identificavam as duas maltas rivais de capoeira. Isto reforça a teoria de que o período de formação das maltas de capoeiras no Rio de Janeiro realmente se deu a partir da metade do século XIX.

As indumentárias dos capoeiras no Rio de Janeiro sofreram muitas modificações no decorrer do século XIX, conforme é possível observar comparando a litografia de Rugendas (1998) com outras representações iconográficas da Capoeira do início do século XX, onde já figuravam os calçados, cintos, lenço de seda, calças e camisas mais elaboradas.

As indumentárias presentes na Capoeira continuam sofrendo modificações até hoje. Os elementos materiais do passado podem ser verificados no presente, portando significados de identidade cultural. A mesclagem entre a moda, a tecnologia dos matérias esportivos, a aplicação dos princípios da especificidade e os usos e os costumes de determinado período com a utilidade e praticidade das indumentárias para a prática da Capoeira se aperfeiçoaram com o tempo, proporcionando um rico repertório de significados e utilidades destes materiais.

\section{Música}

O francês Charles Ribeyrolles, que viveu de 1812 a 1860, esteve no Brasil possivelmente a partir de 1835 e teceu um interessante relato:

No sábado, à noite, finda a última tarefa da semana, e nos dias santificados, que trazem folga e repouso, concedem-se aos escravos uma ou duas horas para a dança. Reúnemse no terreiro, chamam-se, agrupam-se, incitam-se e a festa principia. Aqui é a capoeira, espécie de dança pírrica, de evoluções atrevidas e combativas, ao som do tambor do congo. Ali é o batuque, com suas atitudes lascivas, que o urucungo acelera ou retarda. Mais além é uma dança louca, com a provocação dos seios e das ancas. Espécie de convulsão inebriante a que chama de lundu (RIBEYROLLES apud ABREU, 2005, p. 37).

Constata-se que, em um mesmo local, havia a presença de muitas práticas concomitantemente, proporcionando rica troca de informações e cultura entre os sujeitos e suas respectivas práticas. Esta troca de informações era fundamental para organizações, ações e formas de luta e defesa contra a opressão escravista.

Esta referência acima fornece margens de especulações sobre a relação do tambor do Congo e a pratica da Capoeira naquele período, o que merece um maior aprofundamento em pesquisas. $\mathrm{O}$ tambor é um instrumento musical também constatado na litografia Jogar Capoëra de Rugendas (1998).

As palavras de Ribeyrolles, as quais afirmam que a prática de danças eram concedidas nas folgas, parece contradizer as do pesquisador Passos Neto, o qual afirma que as mesmas eram proibidas e repreendidas (2001). Mas nota-se que, quando tais manifestações eram permitidas, em uma política de aliviamento de tensões sociais, também eram de certa forma vigiadas, mesmo à distância. A proibição de práticas de escravos como as danças não era uma regra. $\mathrm{O}$ aspecto relacional entre permissão e proibição é muito mais complexo e não pode ser analisado fora de uma contextualização sob vários fatores. Contudo, no mesmo período em que 
Charles Ribeyrolles teceu suas considerações e que Rugendas retrata um tambor na litografia Jogar Capoëra, o então Chefe de Polícia Eusébio de Queirós ordena a reconstrução do pelourinho da cidade $^{10}$, que havia sido extinto em $1830^{11}$, e propõe a Câmara Municipal que o Código de Postura da cidade pró́ba tambores nas danças de ruas de escravos ${ }^{12}$.

Mas a presença deste instrumento musical não era deixada de lado em relatos de ofícios policiais na segunda década do século XIX no Rio de Janeiro, principalmente quando na presença do tipo social do capoeira, agravado por 'ajuntamento': "Leão Angola, escravo de José Pedro de Sousa, por ser encontrado em ajuntamentos de capoeiras, achando-se-lhe um tambor pequeno" ${ }^{\text {. }}$. Assim como na litografia de Rugendas, o tambor pode representar o instrumento agregador para se formar uma 'roda', um 'ajuntamento', para o jogo da Capoeira. O tambor pequeno pode sugerir a facilidade para leva-lo a qualquer lugar, devido ao peso reduzido se comparado com os grandes tambores, e para poder escondê-lo, a fim de se livrar da repressão.

\section{Armas e Objetos}

"Pedro Benguela, encontrado no Largo da Carioca jogando capoeira com uma navalha de ponta" 14 em 30 de setembro de 1812, sofreu o primeiro castigo de açoites registrado por uso da navalha no jogo-luta da Capoeira. Esta cena seria corriqueira por todo o século XIX no Rio de Janeiro. Navalhas, facas, estoques, sovelões, paus, pedras, e possivelmente outras peças, foram largamente utilizadas pelos capoeiras. Isto pode ser constatado em inúmeras fontes.

Ao longo do tempo estes aprimoraram não só a habilidade em seu manuseio, mas também, nas outras necessidades pertinentes para o seu uso, como por exemplo, ao precisar se livrar destas armas: "Pena para José Angola de Manuel da Lapa por ser encontrado no largo da Carioca jogando capoeira com uma navalha aberta na mão, que atirou fora quando foi preso..."

Muitas destas habilidades, estratégias e experiências foram desenvolvidas pelo contato com a marinhagem e também militares, como já visto. $\mathrm{O}$ desafio ao poder instituído e a problemática na segurança pública fizeram com que ao final do século XIX a capoeiragem e o uso de armas ou qualquer instrumento ou objeto capaz de produzir lesão corporal constassem no novo Código Penal de
1890.

\section{A materialidade da cultura imaterial}

Neste artigo procurou-se investigar os sentidos da cultura material, pensando os processos múltiplos educativos da Capoeira também pelas coisas, pelo material, entendendo a utilidade dimensão prática - e os signos - dimensão simbólica - desta cultura material, de suas representações, de suas simbologias e dos indícios das ações e utilizações destas coisas.

Pôde-se entender que o conhecimento, pelos capoeiristas, dos lugares e ambientes em que atuavam, assim como os momentos do dia períodos diurno e noturno - eram fundamentais para a realização da prática, na medida em que a respectiva dominação do referido território era fator de identidade de grupo e de status social e estratégia de sobrevivência e proteção. Todo este conhecimento produzido e reproduzido moldou-se e fortaleceu-se em estratégias de defesa, e ataque, e de contra poder às ações de coação e inibição do poder institucionalizado através do século XIX no Rio de Janeiro.

$\mathrm{Na}$ mesma medida, a atividade do jogo, simulacro pedagógico da luta, por várias vezes foi identificada junto à música, caracterizando o elemento lúdico da prática, apesar de não se verificar algum elemento musical próprio e característico da Capoeira. Contudo, era comum a apreensão de instrumentos musicais portados pelos capoeiras, mesmo estes se utilizando de estratégias para evitar tal apreensão, como a utilização de pequenos instrumentos, fáceis de transportar e esconder, como um tambor pequeno, por exemplo.

Estratégias parecidas foram verificadas a fim de evitar prisão pelo porte de arma branca. As armas, apesar de proibidas, poderiam ser encontradas com pessoas de certos ofícios que as requeriam e, principalmente, com marinheiros. A Capoeira foi uma prática que sempre transitou no território dos homens do mar e possivelmente vários conhecimentos foram trocados com pessoas de diferentes partes do mundo. Nos documentos investigados é comum encontrar prisões pelo porte e ataque com diferentes tipos de armas, demonstrando o grande repertório material bélico que os capoeiras detinham.

As indumentárias descreviam o status social, o ofício, entre outras características do povo. Mas só após a metade do século XIX, podem ser percebidas as diferenças entre as indumentárias dos 
capoeiras, quando estes as assumem em suas roupas, cintos, calçados e chapéus. Estas diferenças são características de identidade de grupo que dialogam também com a prática do jogo-luta, como é o caso das cores que identificam as maltas e o corte das calças que facilitam os movimentos dos golpes.

Mas todos estes aspectos da cultura material da Capoeira descritos acima viriam dialogar com as mudanças advindas com a modernidade do início do século XX, juntamente com o início do processo de esportivização e institucionalização da Capoeira e as modificações no cenário urbano, social e político na capital do Brasil. Consequentemente, estas circunstâncias começaram a operar nos processos de saber e fazer do jogo-luta, desta forma, repercutindo diretamente nos processos pedagógicos da Capoeira.

\section{Notas}

1 Livro de ofícios recebidos, livro $\mathrm{n}^{\mathrm{o}} 9.417$ (OR), 4/3/1833, ofício sem número. Serviço de Documentação da Marinha - Arquivo da Marinha (SDM-AM).

2 Ofício da Polícia e Juízes para o Arsenal de Marinha, 1829-1836, 1.9.593, 28/3/1836, ofício 2.167, Serviço de Documentação da Marinha Arquivo da Marinha (SDM-AM).

3 Ofício do Chefe de Polícia ao Ministério da Justiça, Ij6-172, jan.-jul., 1836, Arquivo Nacional.

4 Códice 403, Relação de presos feitos pela Polícia, 1810-1821, Vol. 1, 13/10/1812, Documentação da Secretaria de Polícia da Corte, Arquivo Nacional.

5 Códice 403, Vol. 2, 2/6/1819, Arquivo Nacional.

6 Códice 403, Vol. 2, Ano de 1820, Arquivo Nacional.

7 Códice 403, Vol. 2, 9/8/1821, Arquivo Nacional.

8 Códice 403, Vol. 1, 21/1/1815, Arquivo Nacional.

9 Códice 403, Vol. 2, 10/12/1819, Arquivo Nacional.

10 Ofício 47-2-45 de 1834, Arquivo Geral da Cidade do Rio de Janeiro.

11 Ofício 47-2-44 de 1830, Arquivo Geral da Cidade do Rio de Janeiro.

12 Ofício 6-1-25 de 1833, Arquivo Geral da Cidade do Rio de Janeiro.

13 Códice 403, Vol. 2, 1817-1819, Arquivo Nacional.

14 Códice 403, Vol. 1, 30/9/1812, Arquivo
Nacional.

15 Códice 403, Volume 2, de $1^{\circ}$ de Março de 1820 , Arquivo Nacional.

\section{Referências}

ABREU, F. J. de. Capoeiras - Bahia, séc. XIX: imaginário e documentação, v. 1. Salvador: Instituto Jair Moura, 2005.

CAVALCANTI, G. Do lenço de seda à calça de ginástica. In: Revista de História da Biblioteca Nacional. Disponível em: <http://www.revistadehistoria.com.br/v2/home/?go $=$ detalhe \&id=1771 $>$. Acesso em: 26 abr. 2009. Publicado em: 15 de jun. 2008.

GOMES, L.; NOGUEIRA, M. O Brasil surreal que Dom João encontrou. Revista Super Interessante. 251. ed. - abril, p. 62-71. São Paulo: Abril, 2008.

IPHAN - INSTITUTO DO PATRIMÔNIO HISTÓRICO E ARTÍSTICO NACIONAL. Disponível em: <http://portal.iphan.gov.br>. Acesso em: 23 de nov. 2011.

PASSOS NETO, N. S. Capoeira: os fundamentos da malícia. 8. ed. Rio de Janeiro: Record, 2001.

RUGENDAS, J. M. Viagem pitoresca através do Brasil. Tradução de Sérgio Milliet; ilustrações de Rugendas. Belo Horizonte, Itatiaia: Coleção Reconquista do Brasil, 3, (8), 1998.

SOARES, C. E. L. A capoeira escrava e outras tradições rebeldes no Rio de Janeiro (1808-1850). $2^{a}$ edição revisada e ampliada. Campinas, SP: UNICAMP/Centro de Pesquisa em História Social da Cultura, 2002.

VASSALLO, S. P. O registro da capoeira como patrimônio imaterial: novos desafios simbólicos e políticos. Educação Física em Revista. 2, 1-16, 2008.

UNESCO. Convention for the Safeguarding of the Intangible Cultural Heritage. Paris: UNESCO, 2003. 


\section{Sobre o autor:}

Ricardo Martins Porto Lussac: Doutorando em Educação no ProPEd da UERJ. Possui Mestrado em Ciência da Motricidade Humana pelo PROCIMH da Universidade Castelo Branco, Rio de Janeiro, RJ, Brasil (2009). Pós-graduado em Psicomotricidade, com Complementação Pedagógica em Didática do Ensino Superior pela Universidade Cândido Mendes, UCAM, Rio de Janeiro, RJ, Brasil (2004). É graduado em Educação Física, Licenciatura e Bacharelado pela Universidade Estácio de Sá (2000). Professor da Secretaria Municipal de Educação da Prefeitura da Cidade do Rio de Janeiro.

Recebido em 01/06/2014

Aprovado em 04/11/2014 